\title{
Physical activity in daily life in patients with chronic low back pain.
}

Citation for published version (APA):

Verbunt, J. A. M. C. F., Westerterp, K. R., Heijden van der, G. J., Seelen, H. A. M., Vlaeyen, J. W. S., \& Knottnerus, J. A. (2001). Physical activity in daily life in patients with chronic low back pain. Archives of Physical Medicine and Rehabilitation, 82, 726-730. https://doi.org/10.1053/apmr.2001.23182

Document status and date:

Published: 01/01/2001

DOI:

10.1053/apmr.2001.23182

Document Version:

Publisher's PDF, also known as Version of record

Document license:

Taverne

Please check the document version of this publication:

- A submitted manuscript is the version of the article upon submission and before peer-review. There can be important differences between the submitted version and the official published version of record.

People interested in the research are advised to contact the author for the final version of the publication, or visit the DOI to the publisher's website.

- The final author version and the galley proof are versions of the publication after peer review.

- The final published version features the final layout of the paper including the volume, issue and page numbers.

Link to publication

\footnotetext{
General rights rights.

- You may freely distribute the URL identifying the publication in the public portal. please follow below link for the End User Agreement:

www.umlib.nl/taverne-license

Take down policy

If you believe that this document breaches copyright please contact us at:

repository@maastrichtuniversity.nl

providing details and we will investigate your claim.
}

Copyright and moral rights for the publications made accessible in the public portal are retained by the authors and/or other copyright owners and it is a condition of accessing publications that users recognise and abide by the legal requirements associated with these

- Users may download and print one copy of any publication from the public portal for the purpose of private study or research.

- You may not further distribute the material or use it for any profit-making activity or commercial gain

If the publication is distributed under the terms of Article $25 \mathrm{fa}$ of the Dutch Copyright Act, indicated by the "Taverne" license above, 


\title{
Physical Activity in Daily Life in Patients With Chronic Low Back Pain
}

\author{
Jeanine A. Verbunt, MSc, MD, Klaas R. Westerterp, PhD, Geert J. van der Heijden, PhD, \\ Henk A. Seelen, PhD, Johan W. Vlaeyen, PhD, J. Andre Knottnerus, PhD
}

ABSTRACT. Verbunt JA, Westerterp KR, van der Heijden GJ, Seelen HA, Vlaeyen JW, Knottnerus JA. Physical activity in daily life in patients with chronic low back pain. Arch Phys Med Rehabil 2001;82:726-30.

Objectives: To evaluate disuse (ie, a decreased daily physical activity level) in patients with chronic low back pain (LBP) and to evaluate the construct validity of accelerometry for measuring physical activity in daily life.

Design: Case-control study in a cross-sectional design; comparison of accelerometry to the criterion standard (doubly labeled water technique).

Setting: Normal daily living (unrestricted by the measurement devices).

Patients: Thirteen patients with chronic nonspecific LBP and 13 age- and gender-matched healthy controls.

Main Outcome Measures: Physical activity in daily life, expressed as whole-body acceleration measured with a triaxial accelerometer (Tracmor), and as the ratio between average daily metabolic rate (ADMR), measured by the doubly labeled water technique, and resting metabolic rate (RMR), measured by the ventilated hood. Both techniques were used simultaneously for 14 days.

Results: Mean physical activity level in patients and controls did not differ significantly. The correlation between the Tracmor and ADMR and RMR was .72 $(p<.01)$.

Conclusions: Decreased physical activity levels in this sample of chronic LBP patients was not confirmed. The Tracmor is a valid instrument for measuring daily activity in LBP patients.

Key Words: Activities of daily living; Low back pain; Rehabilitation.

(C) 2001 by the American Congress of Rehabilitation Medicine and the American Academy of Physical Medicine and Rehabilitation

$\mathbf{P}$ ATIENTS WITH CHRONIC low back pain (LBP) often report an intolerance for physical activity. As a result of their back pain problems, patients report a reduced level of such activity. If the reduced level is prolonged, it can result in physiologic changes such as a decrease in muscle mass, in-

From the Rehabilitation Foundation Limburg, Hoensbroek (Verbunt); Institute for Rehabilitation Research, Hoensbroek (Verbunt, van der Heijden, Seelen); and Maastricht University, Maastricht (Westerterp, Seelen, Vlaeyen, Knottnerus), the Netherlands.

Accepted in revised form August 22-27, 2000.

Supported by the Foundation De Drie Lichten in the Netherlands, the Council for Medical and Health Research of the Netherlands (grant no. 904-65-090), and Zorgonderzoek Nederland (grant no. 96-06-006).

Presented in part at the International Association for the Study of Pain's 9th World Congress on Pain, Vienna, 1999.

No commercial party having a direct financial interest in the results of the research supporting this article has or will confer a benefit upon the author(s) or upon any organization with which the author(s) is/are associated.

Reprint requests to Jeanine A. Verbunt, MSc, MD, Institute for Rehabilitation Research, PO Box 192, 6430 AD Hoensbroek, The Netherlands, e-mail: J.Verbunt@irv.nl. 0003-9993/01/8206-6102\$35.00/0

doi:10.1053/apmr.2001.23182 crease in body weight and percentage of body fat, and a decrease in resting metabolic rate. ${ }^{1,2}$ Altogether, these physiologic changes, often referred to as disuse, complicate the initial problem of LBP. As in other chronic disabilities, disuse can play an additional role in the development of a chronic LBP syndrome after an acute back problem. Therefore, it is important to evaluate whether the level of physical activity is decreased in patients with chronic LBP.

Different methods for evaluating physical activity are available, varying from simple patient reports to sophisticated, technically oriented ambulatory monitoring. ${ }^{3}$ Selection of an appropriate evaluation method is primarily based on the specific dimension of physical activity to be evaluated, methodologic quality, and feasibility. The most appropriate method for measuring physical activity levels, and therewith evaluating related physiologic changes, is an objective one that can be used under normal living conditions over a prolonged time period with minimal discomfort to the patient.

In the physiology literature, physical activity is often described in terms of energy expenditure. ${ }^{4}$ Two techniques for measuring energy expenditure associated with physical activity/physical performance are the doubly labeled water technique and accelerometry. Two techniques for measuring this are the doubly labeled water technique and accelerometry. The doubly labeled water technique is generally accepted as the gold standard for physical activity assessment in daily living. ${ }^{5}$ This technique determines the average daily metabolic rate (ADMR) and, with an estimate of basal energy expenditure, provides a reliable measure of energy expenditure associated with physical activity during 1 to 3 weeks. ${ }^{6}$ Schoeller and Hnilicka, ${ }^{7}$ in a summary of studies describing repeated measurements of energy expenditure by doubly labeled water in various subgroups, reported an average coefficient of variation $(\mathrm{CV})$ of $8 \%$. Different subgroups were: young men $(\mathrm{CV}=$ $8.5 \%)$; young women $(\mathrm{CV}=7.8 \%)$; obese women $(\mathrm{CV}=$ $8.8 \%)$; children $(\mathrm{CV}=7.1 \%)$; and men on a hypercaloric diet $(\mathrm{CV}=2.9 \%)$. Despite its good feasibility, the high costs and the need for sophisticated analyses limit the applicability of the doubly labeled water technique.

Accelerometry is based on movement registration with accelerometers that are attached to the body. Research in ergonomics has shown a relation between the integral of the absolute value of body acceleration and oxygen consumption or energy expenditure. ${ }^{8}$ Although unidirectional accelerometers have been used for several years, triaxial accelerometers are now available. Measuring human movement in 3 directions instead of 1 improves the prediction of energy expenditure by using accelerometry. ${ }^{9}$ Data sampling with a 1-minute interval is possible during a measurement period of 14 days, making it possible to measure daily patterns of physical activities. ${ }^{10}$ Meijer et $\mathrm{al}^{11}$ tested the reliability of a triaxial accelerometer (Tracmor ${ }^{\mathrm{a}}$ ) in young adults during a treadmill test. Reproducibility of the signal was $76 \%, 85 \%$, and $95 \%$ at 3,5 , and $7 \mathrm{~km} / \mathrm{h}$, respectively. Kochensberger et al ${ }^{12}$ studied the reproducibility of a triaxial accelerometer in an elderly population (mean age, $71 \mathrm{yr}$ ) and found an average intraclass correlation coefficient 
(ICC) of .81 (range, .77-.88). We must emphasize that reliability in measurement of energy expenditure in daily life, as presented here with accelerometry and doubly labeled water, is also a function of physiologic variation in total energy expenditure and not just analytic error. In healthy persons, accelerometry compared with indirect calorimetry showed a strong relation between accelerometer output and energy expenditure in both an experimental setting $(r=.95)$ and in daily life $(r=$ $.73), 5,9,10,13$ suggesting that accelerometry is a valid measure of physical activity.

Accelerometry may also be a promising instrument for measuring physical activity in patients with chronic LBP. However, it is possible that the instrument's validity may be biased by a different body motion pattern in chronic LBP patients in comparison with healthy persons. Persons with chronic LBP may have a different body motion pattern to avoid worsening their back pain. In a laboratory setting, patients with LBP had less trunk motion during a specific dynamic task than did healthy persons. ${ }^{14}$ Because the accelerometer is fixed around the trunk, resulting in decreased trunk motion, measurement of physical activity in LBP patients by accelerometry can be influenced. This may result in a different correlation between energy expenditure and accelerometer output compared with healthy persons. Before the accelerometer can be used to evaluate physical activity in daily life in chronic LBP patients, its validity must be proven.

The purpose of this study was threefold: (1) to compare accelerometry with the doubly labeled water technique to evaluate its construct validity in measuring physical activity in patients with LBP; (2) to evaluate disuse in chronic LBP patients by comparing their level of physical activity, body mass, and percentage of body fat with a sample of matched healthy persons; and (3) to evaluate the relation between the physical activity level (PAL) and perceived disability in chronic LBP.

\section{METHODS}

\section{Subjects}

Thirteen patients ( 9 men, 4 women) participated in the study. The mean age \pm standard deviation (SD) was $45 \pm 3$ years. All patients had nonspecific LBP with a mean duration of $12 \pm 7$ years, $77 \%$ were employed, and $15 \%$ of the employed were on sick leave because of their back pain. Fifteen percent received disability payments because of back pain problems. Inclusion criteria were: nonspecific LBP for at least 3 months and age between 18 and 60 years. Exclusion criteria were lumbar disc herniation with neurologic complications; major structural back abnormality; evidence of inflammatory, systemic, or neoplastic disease; major psychiatric illness; and pregnancy. Patients entered the study in 2 ways: (1) they were referred by the departments of rheumatology, orthopedics, and rehabilitation medicine of the University Hospital of Maastricht and the Rehabilitation Center of Hoensbroek; or (2) if they had participated in a LBP study some years earlier and still had back pain complaints, they were invited to participate. ${ }^{15}$ All patients gave written informed consent to participate. The experimental protocol was approved by the ethics committees of the Maastricht University and the Rehabilitation Foundation Limburg.

To compare the level of physical activity, body mass, and percentage of body fat of patients and healthy volunteers, data about the 13 volunteers were derived from a database of the Department Human Biology of the Maastricht University. To compare the level of physical activity, body mass, and percentage of body fat of patients and healthy volunteers, data about the 13 volunteers were anonymously derived from a database of the Department of Human Biology of the Maastricht University. Patients and controls were matched for gender and age. Mean age was $45.7 \pm 2.93$ years. The doubly labeled water technique for assessing physical activity and hydrostatic weighing to assess percentage of body fat were used uniformly for both patients and volunteers.

\section{Protocol}

Measurements included resting metabolic rate (RMR), ADMR, physical activity assessed by accelerometry, body mass, body composition, and self-reports of disability, pain intensity, and fear of movement. Measurements were performed in the summer of 1998 at the Department of Human Biology of the Maastricht University. Physical activity in daily life was measured simultaneously with the doubly labeled water technique and an accelerometer for 2 weeks.

Resting metabolic rate. On the first day, RMR was determined in all subjects in standard conditions by an open-circuit ventilated hood system. ${ }^{\mathrm{b}}$ The patients arrived between 7:30 and 8:15 AM, having fasted for 12 hours, to approach basal metabolic rate. After 10 minutes of bed rest, RMR was measured for 20 minutes while the patients watched television in a prone position.

Body composition. Body mass was obtained with an electronic balance before participants consumed any food or drink. The percentage of body fat was measured by hydrodensitometry, ${ }^{16}$ through which body volume is computed as the difference between body mass measured in air and body weight measured during water submersion. Residual lung volume was measured simultaneously with helium dilution. Percentage of body fat was calculated according to the equation of Siri. ${ }^{17}$

Average daily metabolic rate. ADMR was measured by using the doubly labeled water technique according to Westerterp et al. ${ }^{18}$ This method is based on the concept that oxygen in expired carbon dioxide is in isotopic equilibrium with the oxygen in body fluid. A dose of water containing the isotope deuterium and the stable isotope ${ }^{18} \mathrm{O}$ is ingested and allowed to equilibrate with the total body water. Over time, water lost from the body during normal physiologic activity contains the 2 isotopic labels in proportion to their concentrations in the body fluids. The disappearance rate of the 2 stable isotopes can be detected by taking several urine samples during the measurement period. Therefore, on the evening before day 1 , the patient drank a measured amount of ${ }^{18} \mathrm{O}$ and ${ }^{2} \mathrm{H}$, after a baseline urine sample was collected. Urine samples were collected also on days 1,8 , and 15. Isotope abundance in the urine samples was measured with an isotope ratio mass spectrometer. ${ }^{c}$ A maximum difference of $10 \%$ between the 2 weeks of an observation interval of 14 days was accepted, analogous to criteria of Westerterp. ${ }^{18}$ The energy estimates RMR and ADMR were used to reflect the metabolic cost of successive rest and average daily activity. PAL is the ratio of ADMR to RMR and indicates the overall level of physical activity relative to the rest metabolic rate. A higher PAL indicates a higher level of daily activity.

Physical activity. A triaxial accelerometer ${ }^{\mathrm{a}}$ (dimensions, $7 \times 2 \times 0.8 \mathrm{~cm}$; weight, $30 \mathrm{~g}$ ), consisting of 3 uniaxial piezoresistive accelerometers, was used to record the amount of body movement. The accelerometer was attached to the subject's lower back. Acceleration signals from the 3 measurement directions (posterior, mediolateral, longitudinal axes of the trunk) were amplified and filtered according to Bouten et al. ${ }^{5}$ The rectified and integrated acceleration from all 3 directions for 1 minute was calculated. The number of occasions on which this signal exceeded a predefined threshold was calculated. The data are the output of the accelerometer and are expressed in 
counts per minute (we refer to this output as Tracmor output). Data collection continued uninterrupted for 14 days. Output was stored in a data memory chip within the accelerometer and read by a computer after 14 days. Patients attached the Tracmor around the waist with an elastic belt. They were instructed to wear it during waking hours for 14 days, except during bathing, showering, or swimming. In addition, they recorded in a diary the time they attached the Tracmor to the body in the morning and the time they took it off in the evening. If they had to remove the Tracmor during the day, the reason and the exact time of removal was recorded. Physical activity in daily life was expressed as the total sum of counts registered during waking hours in 14 days.

Patient reports. To score the perceived level of distress and current pain, the patients completed these questionnaires: the Dutch version of the Roland Disability Questionnaire (RDQ), scoring low back disability ${ }^{19}$; the Dutch version of the Tampa Scale for Kinesiophobia (TSK), scoring fear of movement ${ }^{20}$; and a visual analog scale (VAS), scoring current pain intensity on a scale ranging from 0 (no pain) to 100 (unbearable pain). ${ }^{21}$

Statistical analysis. Results were expressed as means \pm SDs. Comparisons between the 2 groups were performed by using the Mann-Whitney $U$ test for unpaired observations ( $\alpha=$ $.05)$. Bivariate correlations between the doubly labeled water technique and the accelerometer were performed by Spearman's rank-order correlation $\left(r_{s}\right)$.

\section{RESULTS}

The test result of the doubly labeled water technique of 1 patient showed an inconsistency between the first and the second week and was therefore excluded from further analysis according to the criteria presented in the Method section.

\section{PAL: Chronic LBP Patients Compared With Healthy Controls}

PAL measured by the doubly labeled water technique did not differ significantly between the patients and healthy controls (table 1). There were no significant differences in the physiologic parameters of body mass and percentage of body fat. Mean resting metabolic rate seemed lower in both men and women compared with the healthy controls, though the difference did not reach the predetermined level of significance.

\section{Tracmor Versus Doubly Labeled Water Technique}

The correlation between measurement of physical activity in chronic LBP patients with the doubly labeled water technique,

Table 1: Physiologic Parameters Concerning Physical Activity

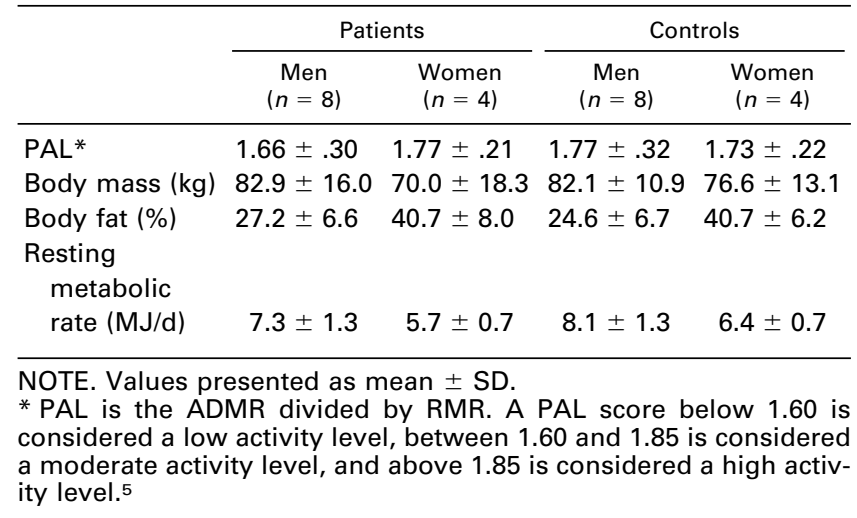

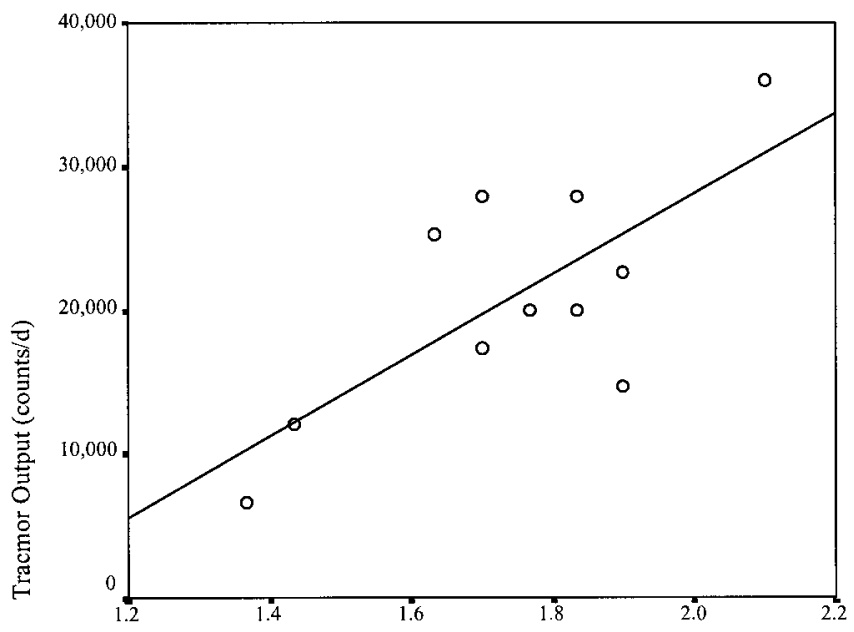

PAL

Fig 1. Relationship between daily physical activity level and Tracmor output.

expressed in PAL and the accelerometer, was .72 $(p<.01)$. Figure 1 shows the correlation between the results of both techniques. When energy expenditure was expressed as ADMR - RMR, corrected for body mass, the correlation was $.63(p<.05)$.

\section{Patients' Reports and Physical Activity}

The mean score for subjective disability on the RDQ was $12.5 \pm$ 7.4. Mean score of fear of movement on the TSK was $42.8 \pm 9.3$. Mean pain intensity, scored on a VAS scale, was $33.7 \pm 27.2$. There were no significant correlations between physical activity in daily life, measured with both the doubly labeled water technique and the accelerometer, and subjective disability, measured by RDQ (table 2). Furthermore, fear of movement, measured by the TSK, and current pain intensity, measured by a VAS, showed no significant correlation with physical activity.

\section{DISCUSSION}

We used the nonparametric Mann-Whitney $U$ test, a nonparametric statistical test, for statistical analysis, because the data were clearly skewed. They did not satisfy the gaussian distribution assumptions, which is likely the result of the criteria and procedure of patient selection, combined with the small number of patients. Bivariate correlations between the doubly labeled water technique and the accelerometer were also performed by a nonparametric statistical test (Spearman's rank-order correlation). Although nonparametric statistical tests provide more conservative results, the shown correlation coefficient was sufficiently large and was statistically significant.

Table 2: Correlation of Daily Physical Activity and Patient Reports

\begin{tabular}{lcccc}
\hline & \multicolumn{4}{c}{ Physical Activity } \\
\cline { 2 - 4 } \cline { 4 - 5 } Patient Reports & \multicolumn{2}{c}{ Accelerometer } & & \multicolumn{2}{c}{ PAL } \\
\cline { 2 - 5 } \cline { 4 - 5 } RDQ & .10 & .76 & -.06 & .74 \\
TSK & .10 & .77 & -.28 & .53 \\
VAS pain intensity & -.06 & .86 & .25 & .44 \\
\hline
\end{tabular}


The first purpose of the study was to investigate the relation between physical activity in daily life measured by the accelerometer and the doubly labeled water technique in patients with chronic LBP. The correlation found in the LBP patients was in good agreement with the correlation found in healthy populations. ${ }^{5,9-11}$ The results showed that in this group of patients the correlation was not negatively affected by a different body movement pattern in comparison with healthy persons. In other words, the energy expenditure during physical activity in chronic LBP patients was comparable to the energy expenditure in healthy persons. These results imply that accelerometry correlates with energy expenditure in LBP patients as it does in healthy persons, and the construct validity of the accelerometer for measuring the patients' physical activity level appears to be sufficient.

In both patients and healthy volunteers, no perfect match was found between the different measurement methods of physical activity. Two aspects must be considered: the influence of diet-induced thermogenesis on energy expenditure, and the influence of static exercise on accelerometry. Diet-induced thermogenesis is energy metabolism stimulated by the ingestion of food and it involves about $10 \%$ of ADMR. ${ }^{22}$ Because this process influences the outcome of energy expenditure with doubly labeled water and does not effect assessment of body acceleration, there can be a discrepancy between both methods. In the present study, and the related studies ${ }^{5,9,10,13}$ in healthy controls, the influence of diet-induced thermogenesis was not accounted for and therefore it may be that the reported correlation underestimates the true correlation. Second, energy expenditure during static exercise must be considered. Static exercise results in an increase in energy expenditure without any body movement and therefore can create a discrepancy between outcomes of the 2 methods for assessing physical activity. However, in contrast to energy used by diet-induced thermogenesis, the contribution of static exercise to daily physical activity is almost negligible. ${ }^{23}$ Therefore, the influence of static exercise is not a serious limitation in measuring energy expenditure over a prolonged period. Given the comparable correlation in chronic LBP patients and a healthy population, it is suggested that the accelerometer can be used for valid assessment of physical activity in patients with chronic LBP.

The second purpose of this study was to investigate disuse in chronic LBP patients compared with healthy controls. The mean level of daily physical activity in the LBP patients did not differ from that of their gender- and age-matched healthy controls. The PAL measured in both the patients and the controls was in good agreement with PAL criteria of the World Health Organization. ${ }^{24}$ RMR showed a decreased level in the patient group compared with the controls, but this failed to attain significance. No difference between the 2 groups was found in the physical activity-related parameters of percentage of body fat and body mass, which is in agreement with the findings of Hultman et al. ${ }^{25}$ In interpreting differences in RMR and percentage of body fat, the reliability of the measurement methods must be considered. Leff et $\mathrm{al}^{26}$ found in young healthy adults an ICC of RMR measured by ventilated hood ranging from .70 to .98 . The largest variability was found at the beginning of the measurement period, when patients were adapting to the calorimetry equipment. For this reason, we started our measurements after an initial period of 10 minutes. Furthermore, reliability of body composition measured by hydrodensitometry was high in a study reported by Katch et al,27 with a test-retest reliability coefficient of .94. Given the comparable mean level of physical activity in daily life in both groups, no differences were expected in the physiologic pa- rameters because they reflect the physiologic consequence of a long-term level of physical activity in daily life.

There is, however, a possibility that the patients participating in this study were in a relatively better physical condition than other patients with chronic LBP. As reported in the Methods section, $77 \%$ of the patients were employed despite their back problems. Although patients could be referred to the study by medical specialists in a university hospital and a rehabilitation center, no patients from the rehabilitation center entered the study. They matched one of the exclusion criteria or they did not want to participate. In LBP patients who need the care given in a rehabilitation center, physiologic changes caused by their worse physical condition could be different from the patients in this study. The postulated presence of disuse in patients with chronic LBP could not be confirmed in our group of patients. Further investigation seems warranted.

It is remarkable that though patients felt disabled because of their back problem, as shown in their RDQ scores, their level of physical activity was not lower in comparison with the level of physical activity in the healthy controls. The patients' RDQ scores were above the mean RDQ scores $(9.5 \pm 5.8)$ in a comparable population of 338 persons with chronic LBP. ${ }^{19}$ No correlation was found between subjective disability, as measured by the RDQ, and physical activity, measured by both accelerometry and doubly labeled water. There was also no correlation between pain intensity and physical activity levels. These findings are in line with previous research. For example, Vendrig and Lousberg ${ }^{28}$ reported within-subject correlations between pain intensity, mood, and activity level. Pain intensity was significantly associated with mood, but not with physical activity. Linton ${ }^{29}$ found a relation between physical activity and pain intensity in global interview reports, but this relationship gradually disappeared as the measure of physical activity became more overt and objective. Schmidt ${ }^{30}$ found that patients with chronic LBP were less capable of estimating their physiologic level of exertion in a performance test situation compared with healthy controls. In general, patient reports, as recorded in diaries and questionnaires, reflect patients' perceptions and cognitive evaluations of the variable of interest. For instance, changes in the perception of being disabled may be considered in the reported outcome. In measurement of physical activity, this can result in a totally different patient report about the activities in daily living compared with his actual behavior, expressed in physiologic parameters. This finding emphasizes the need to use objective methods to measure physical activity and to avoid self-report of physical activity if physiologic factors, rather than behavioral factors, are of interest.

We could not confirm the postulated presence of disuse in patients with chronic LBP in this study. As stated, it is important to include patients referred to tertiary care in further research. It is also noticeable that in a cross-sectional study such as this one, no data can be obtained about the changes in physical activity within a person. An alternative approach to the within-person changes is to compare the patient group with a group of healthy controls, assuming that the patients acted as the controls before the back pain began. However, to monitor the process of disuse, it is more appropriate to measure withinperson changes in physical activity levels and such related parameters as percentage of body fat and body weight. For this reason, a longitudinal study design is preferred.

\section{CONCLUSION}

The triaxial accelerometer is a valid instrument for measuring daily activity in patients with chronic LBP. The mean level of physical activity did not differ in chronic LBP patients when 
compared with a healthy population, and the presence of disuse in chronic LBP was not confirmed. The discrepancy between measured physical activity and patient reports gives emphasis to the need to use an objective measurement if physiologic factors are of interest.

Acknowledgments: The authors thank Peter Heuts and Kees Pons for their contributions to the study.

\section{References}

1. Convertino VA, Bloomfield SA, Greenleaf JF. An overview of the issues: physiological effects of bed rest and restricted activity. Med Sci Sports Exerc 1997;29:187-90.

2. Pratley R, Nicklas B, Rubin M, Miller J, Smith A, Smith M, et al. Strength training increases resting metabolic rate and norepinephrine level in healthy 50- to 65-yr-old men. J Appl Physiol 1994; 76:133-7.

3. Bussmann JB, Stam HJ. Techniques for measurement and assessment of mobility in rehabilitation medicine: a theoretical approach. Clin Rehabil 1998;12:513-22.

4. Ainsworth BE, Haskell WL, Leo AS, Jacobs DR, Montoye HJ, Sallis JF, et al. Compendium of physical activities: classification of energy costs of human physical activities. Med Sci Sports Exerc 1993;25:71-80.

5. Bouten CV, Verboeket-van de Venne WP, Westerterp KR, Verduin M, Janssen JD. Daily physical activity assessment: comparison between movement registration and doubly labeled water. J Appl Physiol 1996;81:1019-26.

6. Schoeller DA. Measurement of energy expenditure in free living humans by using doubly labeled water. J Nutr 1988;118:1278-89.

7. Schoeller DA, Hnilicka JM. Reliability of the doubly labeled water method for the measurement of daily energy expenditure in free living subjects. J Nutr 1996;126:348S-54S.

8. Cotes JE, Meade F. The energy expenditure and mechanical energy demand of walking. Ergonomics 1960;3:97-119.

9. Chen KY, Sun M. Improving energy expenditure estimation by using a triaxial accelerometer. J Appl Physiol 1997;83:2112-22.

10. Bouten CV, Westerterp KR, Verduin M, Janssen JD. Assessment of energy expenditure for physical activity using a triaxial accelerometer. Med Sci Sports Exerc 1994;26:1516-23.

11. Meijer GA, Westerterp KR, Verhoeven FM, Koper HB, de Hoor F. Methods to assess physical activity with special reference to motion sensors and accelerometers. IEEE Trans Biomed Eng 1991;38:221-9.

12. Kochensberger G, McConneell E, Kuchibhatla M, Pieper C. The reliability, validity and stability of measure of physical activity in the elderly. Arch Phys Med Rehabil 1996;77:793-5.

13. Westerterp KR. Physical activity assessment with accelerometers. Int J Obes Relat Metab Disord 1999;23 Suppl 3:45-9.

14. Rudy TE, Boston JR, Lieber SJ, Kubinski JA, Delitto A. Body motion patterns during repetitive wheel rotation task. A comparative study of healthy subjects and patients with low back pain. Spine 1995;20:2547-54.
15. Beurskens A, de Vet HC, Koke AJ, Lindeman E, Regtop W, van der Heijden GJ, et al. Efficacy of traction for non-specific low back pain: a randomised clinical trial. Lancet 1995;346:1596-600.

16. Meijer GA, Westerterp KR, Seyts GH, Janssen GM, Saris WH, ten Hoor F. Body composition and sleeping metabolic rate in response to a 5-month endurance training programme in adults. Eur J Appl Physiol 1991;62:18-21.

17. Siri WE. Gross composition of the body. In: Lawrence JH, Tobias CA, editors. Advances in biological and medical physics. Vol 4. New York: Academic Pr; 1956. p 239-80.

18. Westerterp KR, Wouters L, van Marken Lichtenbelt WD. The Maastricht protocol for the measurement of body composition and energy expenditure with labeled water. Obes Res 1995;3:49-57.

19. Gommans JH, Koes BW, van Tulder MW. Validiteit en responsiviteit Nederlandstalige Roland Disability Questionnaire. Vragenlijst naar functionele status bij patienten met lage rugpijn. Ned Tijdschr Fysiother 1997;107:28-33.

20. Vlaeyen JW, Kole-Snijders AM, Rotteveel AR, Ruesink R, Heuts $\mathrm{PH}$. The role of fear of movement/(re)injury in pain disability. J Occup Rehabil 1995;5:235-52.

21. Bolton JE. Accuracy of recall of usual pain intensity in back pain patients. Pain 1999;83:533-9.

22. McArdle WD, Katch FI, Katch VL. Exercise physiology. Energy, nutrition and human performance. 4th ed. Baltimore (MD): Williams \& Wilkins; 1996.

23. Saris WH, Binkhorst RA. The use of the pedometer and actometer in studying daily physical activity in man. Part II: validity of the pedometer and actometer in measuring the daily physical activity. Eur J Appl Physiol 1977;37:229-35.

24. World Health Organization. Energy and protein requirements, report of a joint FAO/WHO/UNO expert consultation. Geneva: WHO; 1985. Technical Report Series 724.

25. Hultman G, Nordin M, Saraste H, Ohlsen H. Body composition, endurance, strength, cross-sectional area, and density of mm erector spinea in men with and without low back pain. J Spinal Disord 1993;6:114-26.

26. Leff ML, Hill JO, Yates AA, Cotsonis GA, Heymsfield SB. Resting metabolic rate: measurement reliability. JPEN J Parenter Enteral Nutr 1987;11:354-9.

27. Katch F, Michael ED, Horvath SM. Estimation of body volume by underwater weighing: description of a simple method. J Appl Physiol 1967;23:811-3.

28. Vendrig AA, Lousberg R. Within-person relationships among pain intensity, mood and physical activity in chronic pain: a naturalistic approach. Pain 1997;73:71-6.

29. Linton SJ. The relationship between activity and chronic back pain. Pain 1985;21:289-94.

30. Schmidt AJ. Cognitive factors in the performance level of chronic low back pain patients. J Psychosom Res 1985;29:183-9.

\section{Suppliers}

a. Maastricht University, PO Box 616, 6200 MD Maastricht, The Netherlands.

b. Oxycon Beta; Jaeger BV, PO Box 299, 3720 AG, Bilthoven, The Netherlands.

c. Aqua Sira; VG Isogas, Inc, Road 3, Cheshire CW7 3GA, UK. 